\title{
UNAS MAESTRAS QUE DEJARON HUELLA: RASTREANDO EN LA MEMORIA DE LAS MAESTRAS RURALES
}

Teresa González Pérez *

\begin{abstract}
RESUMEN
La educación en España durante el siglo XX ha experimentado un notable avance, aunque con diferencias importantes según los espacios geográficos. La realidad escolar ha marchado al ritmo de los acontecimientos sociopolíticos, tanto en las escuelas urbanas como en las escuelas rurales. Desde las esferas oficiales las escuelas rurales no gozaron de atención especial ni tampoco contaron con un modelo de formación inicial para maestras rurales. Nuestro objetivo es dar a conocer la experiencia de las maestras rurales en Canarias (España) recurriendo a su relato autobiográfico. En su narración nos muestran sus vivencias y experiencia profesional, información que constituye una fuente valiosa para la investigación, aunque con el inconveniente de que la memoria oral solo nos permite acercarnos hasta donde nuestras informantes mantienen activas sus vivencias y vivos sus recuerdos.
\end{abstract}

Palabras-clave: Maestras rurales. España. Memoria. Pobreza. Sexismo

\begin{abstract}
SOME TEACHERS WHO LEFT THEIR MARK: TRACKING THE MEMORY OF RURAL TEACHERS

Education has seen remarkable progress in Spain during the twentieth century, although with significant differences according to geographical areas. The school has really gone to the pace of socio-political events in schools, in both urban and rural schools. In official circles, rural schools did neither enjoy special attention, nor have a model of initial training for rural teachers. Our goal is to present the experience of rural teachers in the Canary Islands (Spain) using their autobiography. In their narrative, they show us their experiences and expertise, information that constitutes a valuable resource for research, but the disadvantage of oral memory only allows us to go $t$ where our informants kept alive their experiences and their memories alive.
\end{abstract}

Keywords: Rural teachers. Spain. Memory. Poverty. Sexism.

\footnotetext{
* Profesora Titular de Universidad. Facultad de Educación. Universidad de La Laguna (España).Doctora en Historia. Licenciada en Historia. Licenciada en Filosofía y Ciencias de la Educación (Sección de Ciencias de la Educación). Maestra (Ciencias Humanas). Dirección postal: Facultad de Educación. Universidad de La Laguna. Campus Central. Avda. Trinidad, s/n. 38204 San Cristóbal de La Laguna (Tenerife-España). teregonz@ull.es
} 


\section{Introducción}

La evolución de la educación femenina en Canarias se ubica en el marco de una sociedad en proceso de modificación, registrada en el seno de sociedad que dependía de la administración centralista del Estado español y, por lo tanto reflejaba una situación de dependencia política, social, cultural y económica. En tiempos pretéritos la educación del pueblo canario estaba en un lamentable estado de abandono. Esa situación se hizo más notoria en el caso del sexo femenino, debido a los prejuicios de la época que influían decisivamente en el tipo de educación que la mujer debía recibir, basada en el perfeccionamiento de los quehaceres domésticos. La opinión pública fue desfavorable a que la educación femenina se extendiera a otros parámetros que no fueran prepararla para que cumpliera bien su papel de esposa y madre, planteamiento que dificultó que la mujer aprendiera y pusiera en práctica actividades de tipo intelectual. Además, dado el alto índice de analfabetismo, el peso de las tradiciones y el rigorismo moral, la formación de la mujer se apoyaba fundamentalmente en el dominio de la transmisión oral. Los sectores populares quedaban mayoritariamente al margen del proceso educativo. Muchos pueblos de las Islas carecían de escuelas de niñas, incluso en algunas zonas la escolarización femenina fue tardía y no contaron con escuelas públicas femeninas hasta bien avanzado el siglo XX. La educación de las mujeres fue insuficiente, lo cual sumado al número de escuelas existentes y a la concepción de los programas, produjo como resultado que una reducida cantidad de niñas disfrutara de los beneficios de la educación y que la misma fuera elemental e incompleta en comparación con la impartida a los niños (GONZÁLEZ, 1998).

Las maestras desempeñaron una función crucial en el ámbito rural, sobre todo en las zonas alejadas y marginadas por su secular atraso las maestras eran la única fuente de sabiduría con la que tenían contacto las niñas y las mujeres isleñas. Buena parte de las veces influyeron en su comportamiento, renovaron actitudes y posibilitaron cambios en su vida. Ellas les enseñaron además de los conocimientos básicos (lectura, escritura, aritmética, geometría, geografía, historia, religión y catecismo) a coser, a desarrollar habilidades con la aguja, algo de cocina, puericultura y, sobre todo, contribuyeron a refinar sus rudos modales. No obstante, considerar que las maestras con la influencia de los medios de comunicación y la incorporación activa de las mujeres a la sociedad han perdido el protagonismo de antaño, y no tienen la misma fuerza moral que tuvieron antes de la década de 1980. Una de las características de las escuelas rurales en el pasado es la precariedad, la carencia de recursos escolares así como pésimas condiciones de vida de las maestras y de la población. Las historias se repiten en diferentes lugares del orbe, en distintos países y continentes (GONZÁLEZ Y LÓPEZ, 2009). El reconocimiento a la aportación de las maestras rurales en distintas partes del orbe ha quedado de manifiesto en diversos actos, congresos y publicaciones, como lo ha sido por ejemplo el caso de algunas maestras españolas cuyas historias de vida han sido recogidas en Historia de una Maestra (ALDECOA, 1991), en Retratos de Maestras (VARIAS AUTORAS, 2005) o La voz del olvido. Maestras de ayer (GONZÁLEZ, 2007).

El objetivo de este trabajo es aproximarnos a conocer la actividad que realizaron las maestras en los espacios rurales de las Islas Canarias (España), archipiélago atlántico situado al noroeste de África. Esas mujeres portadoras del saber en las áreas alejadas de las zonas urbanas que han cumplido una doble misión, no sólo como alfabetizadoras sino como mujeres que introdujeron novedades en la vida cotidiana, y que ejercieron una notable influencia en el devenir de la comunidad donde desempeñaron su actividad laboral.

La información que facilita la historia escrita no recoge la vida cotidiana, pues los voceros de los grupos dominantes ignoran las vivencias populares. Los grandes relatos de la historia han quedado desfasados por el uso de nuevas técnicas de investigación. Las fuentes orales, a través de diversas metodologías, suministran cantidad de información. La oralidad ayuda a reconstruir el pasado, recuperando los datos que la gente guarda en su memoria y que no figura registrado en los documentos escritos. Es decir, contribuye a romper la monovisión histórica (VATTIMO, 1991, p. 80) a recuperar una información sustentada en las vivencias cotidianas de la gente cuya fuente básica era la palabra (FRASER, 1994, p. 80). En este estudio aportamos voces y testimonios del pasado educativo reciente, aprovechando que el recurso de la oralidad y la imagen etnográfica 
reportan valiosa información sobre el quehacer educativo; se trata de la recuperación de la memoria a través de los testigos (GOODSON, 2004; IMBERNÓN, 2005). La oralidad también equivale a una narración objetiva, por ello empleamos la metodología del diseño etnográfico. Estimamos la importancia de elaborar un cuestionario pero no ignoramos que la espontaneidad y la frescura de la memoria quedarían entonces invalidadas. Por ello, recurrimos a las historias de vida que reflejan el acontecer y tarea cotidiana tal como recuerdan sus protagonistas.

Al margen de su indiscutible función en las zonas rurales, las maestras no han sido valoradas ni reconocidas, siendo uno de los motivos por los que se retraen en el momento de la entrevista y son muy parcas en sus expresiones. Ha sido necesario crear un ambiente dialogante adecuado y un clima de confianza en el que las maestras pudieran hablar sobre su trabajo. Es a partir de la toma de contacto y el conocimiento previo del interés de la investigación que desarrollamos cuando pudimos plantear una metodología siguiendo un proceso interactivo. Toda la información recuperada ha sido desde la perspectiva de cada una de las personas, desde el significado subjetivo con el que construyeron su memoria vital. Sus relatos autobiográficos los recogemos a través de entrevistas semiestructuradas. Las maestras relatan sus vivencias, sus vicisitudes en un entorno que a veces se les vuelve hostil. Los pueblos donde fueron destinadas se convirtieron en su nueva morada. Vivían allí durante el periodo escolar, se integraron en la vecindad y establecieron vínculos con sus gentes. Sólo presentamos una muestra de una investigación más amplia, donde hemos constatado una historia de esfuerzos que realizaron desde temprana edad y no únicamente desde el momento que decidieron formarse como maestras para acceder al ejercicio profesional.

\section{La Compleja Tarea De Las Maestras Rurales}

Desde la segunda mitad del siglo XIX en España las Escuelas de Magisterio adquirieron relevancia como centros para la formación de las mujeres, pues eran las únicas instituciones educativas, al margen de las escuelas de enseñanza primaria, que promocionaban la cultura femenina (GONZÁLEZ, 1994; GUZMÁN, 1973 y 1986; MELCÓN, 1992; MOLERO, 1989; ORAMAS, 1992).

Hasta la primera década del siglo XX las españolas no tuvieron acceso formalmente a los estudios de bachillerato y universitarios. En el caso de Canarias el retraso educativo fue considerable, ya que no hubo escuela de Magisterio femenina hasta 1902 (GONZÁLEZ, 1997, p.89). Administrativamente la educación dependía del distrito universitario de Sevilla hasta 1927 año en que se creó la Universidad de La Laguna (Tenerife); sumar a ello el desinterés por la educación de las autoridades del gobierno central y representantes locales. A lo anterior añadir que en España no hubo Escuelas Normales Rurales; la formación inicial de las futuras profesionales se regía por un patrón genérico donde privaba el modelo de educación urbano. A pesar de todas las dificultades y la escasez de medios que tuvieron que flanquear, ésta institución fue crucial como centro de formación que irradió cultura y se proyectó en las clases populares, llevando la cultura letrada a los rincones más alejados de la geografía insular. Las maestras se formaron siguiendo un currículum diferenciado, sexuado y que igualmente lo impartían siguiendo la normativa vigente (GONZÁLEZ, 2007). Ellas aprendieron y enseñaron a ser mujer; orientaron a sus alumnas al papel social que estaban destinadas a desempeñar, además que el currículo escolar incorporaba materias específicas: las Enseñanzas del Hogar. Ellas asumieron el mensaje de la domesticidad y lo proyectaron en la escuela, el espacio donde fueron protagonistas. Aprendieron a enseñar, pero inventaron y reinventaron en la praxis diaria del aula, sin apenas recursos fueron capaces de entusiasmar e ilusionar a los niños y niñas en el aprendizaje, motivándolos para incursionar en el mundo de las letras y los números. Con dedicación prioritaria durante años en las escuelas, el propio alumnado legitimó su labor con la asistencia diaria y seguimiento de su tarea. Las maestras de ayer testimonian estilos diferentes de entender la labor docente, de un quehacer aplicado a las escuelas rurales unitarias y a veces graduadas (GONZÁLEZ, 2007). La cultura escolar como modelo formativo planteaba retos en la práctica, una cultura empírico-práctica que ha ido construyendo el magisterio en el ejercicio de su profesión (ESCOLANO, 2002, p.202). 
Las maestras cumplían con un compromiso educativo, con una trayectoria profesional implicada en la tarea de enseñar y, a la vez, de aprender para enseñar. Pertenecen a periodos sociales y políticos diferentes, su procedencia social también diversa, unas hijas de agricultores, otras comerciantes y maestros. Todas cursaron estudios en la Escuela de Magisterio de La Laguna (Tenerife) y casi todas tienen en común que les tocó ejercer durante la etapa dictatorial del general Franco, y tuvieron que someterse a los dictados ideológicos del régimen y amoldarse a la escuela nacionalcatólica (GONZÁLEZ, 2001, p. 369-86). Pero construyeron una escuela más allá de las consignas del régimen, y sobre todo en el tardo franquismo, cuando se flexibilizó el rígido control que presionaba la acción educativa; pues no ignoramos como se vehiculaba ideología a través de la escuela tarea en la que era crucial la labor de los maestros y maestras. Sin embargo, no se arredraron, renovaron su ilusión y compromiso con la infancia, y con una escuela diferente. Estas maestras ejercieron en tiempos difíciles, algunas lo hicieron en los duros años de la posguerra, y forjaron con su educación a personas nuevas.

Nos encontramos con maestras de diversa procedencia, con ideas y formación distinta, y una singular manera de plasmar la práctica. Algunas estudiaron y ejercieron en el primer tercio del siglo XX, como Baldomera María García Fuentes o hasta avanzado el siglo como Concepción García Suárez, que cursaron el Plan de 1914, un plan de estudios que estuvo vigente hasta 1931. Las otras maestras cursaron el Plan 1950, bajo gobierno de la dictadura militar del general Francisco Franco (GONZÁLEZ, 2000, p.167-234). Además a estás últimas se le exigía para el ingreso en la Escuela Normal los certificados de buena conducta moral y patriótica firmado por el alcalde o el jefe de policía, así como un certificado del cura párroco que atestiguara que era cristiana practicante. Todas tuvieron que realizar el albergue preceptivo, que exigía la normativa, organizado durante 15 días en régimen de internado por la Sección Femenina. Podíamos presentar muchas historias de vida de maestras rurales en Canarias, pero las dimensiones requeridas para esta aportación impiden excedernos en el espacio. En este trabajo recogemos la memoria autobiográfica de cinco maestras que se formaron y ejercieron en el siglo XX.

\section{Rememorando el ayer. Historias de vidas profesionales}

\subsection{Maestras del plan de 1914.}

Al igual que en el resto del Estado español la formación de maestros en La Laguna regido por el Plan de 1914 se apoyó en el predominio de los elementos culturales y enciclopedistas, lo cual iba en detrimento de la instrucción pedagógica, y por supuesto, con notable presencia de las enseñanzas del hogar. Para acceder a la formación inicial se requerían estudios primarios.

La primera maestra que entrevistamos, Concepción García Suárez, ejerció como maestra en varios pagos rurales del sur de Tenerife y la otra, Baldomera Maria García Fuentes, como maestra de Ravelo, pago rural del municipio norteño del Sauzal. Concepción García Suárez en la actualidad ha fallecido pero gozó de noventa y siete años de vida. Baldomera, conocida por Maruca, ha superado el siglo y vive con plenas facultades mentales cuidada por su familia. Ambas estudiaron magisterio siguiendo el Plan Cultural o Plan 14 que se estableció en la Normal de Maestras La Laguna. Las maestras Concepción García Suárez y Baldomera Maria García Fuentes fueron además las primeras alcaldesas de Tenerife, tras las elecciones de 1933 bajo gobierno republicano, dándose la circunstancia de ser la primera vez que las mujeres podían votar al tiempo que ocupar un espacio público. En este caso por ser las funcionarias más jóvenes del municipio donde ejercían la docencia fueron designadas alcaldesas. Si bien por breve espacio de tiempo, marcaron un hito en aquél contexto aunque ambas no fueran conscientes de la importancia de ese nombramiento y el significado que tendría varias décadas más tarde en cuanto al empoderamiento de las mujeres. Ellas respondieron a lo políticamente correcto, asumieron el cargo y luego lo traspasaron a un hombre como era esperable en aquel contexto. Permanecieron ajenas al debate feminista, ignoraban los objetivos que perseguían los movimientos de mujeres al tiempo que desconocían a las mujeres pioneras en la política española.

Fui la primera y única alcaldesa hasta ahora de Santiago del Teide, aunque ejercí el cargo poco tiempo 
(5 de febrero de 1933 al 10 de mayo 1933)1. Primero atendía a mi escuela y los domingos por la mañana los dedicaba al Ayuntamiento. Bajaba caminando los $5 \mathrm{Km}$ que separaban Arguayo hasta el ayuntamiento para firmar, despachar los asuntos de trámite y reunirse en sesión a las 10 de la mañana. Los asuntos urgentes me los llevaban al pueblo y/o la llamaban por teléfono (sólo había un teléfono) (Concepción García Suárez, mayo 2000).

Esta maestra se comprometió con su cargo político, tenía sus proyectos para mejorar las condiciones de vida de los vecinos, entre ellos solicitar al Cabildo la continuidad de las obras de la pista que enlazaba desde Tamaimo a la playa y así crear puestos de trabajo para remediar la crisis económica, y lo consiguió. Pero se implicó especialmente en los problemas de Arguayo: pedir una escuela unitaria para niñas y la red de agua, mejorar el trazado de las calles. Los vecinos le ayudaban en realizar el trabajo gratuitamente. No descansó hasta conseguir la subvención para la red de agua potable 2 .

Me trasladé a Santa Cruz y me entrevisté con el Presidente del Cabildo de Tenerife a quien le expuso el grave necesidad del agua y le concedió la subvención de 15.000 Pts. Con tal cantidad adquirió la tubería y los vecinos se encargaron de realizar el trabajo gratuitamente, gracias a su gestión tuvieron agua aunque ella no la disfrutó porque ya había sido trasladada a San Miguel de Abona. También se entrevistó con el Gobernador Civil y no duda en desplazarse hasta la capital para resolver con las autoridades las necesidades más perentorias de los vecinos (entrevista, mayo 2000).

Concepción estuvo de maestra en Arguayo hasta el 8 de julio de 1933 como maestra interina. Más tarde fue nombrada para la escuela de Tamaide en San Miguel de Abona, tomando posesión el 14 de julio de 1933 como maestra propietaria, lugar donde permaneció hasta su jubilación. No volvió a tener contactos con la política pero mantuvo un grato recuerdo de su paso por la Alcaldía. Los vecinos también gozan del agradecimiento por su impecable gestión. Tras la instauración democrática,

\footnotetext{
1 "Santiago del Teide y su Alcaldesa". Diario Hoy. Santa Cruz de Tenerife, 10 de febrero de 1933.

2 Actas Capitulares del Ayuntamiento de Santiago del Teide. Sesión ordinaria del 12 de marzo de 1933. "Acuerdo sobre el agua potable del pago de Arguayo".
}

el ayuntamiento de Santiago del Teide la reconoció con un acto de homenaje a la única Alcaldesa del municipio y colocó una foto suya en el Salón de Plenos de las Casas Consistoriales. También en San Miguel de Abona, el último municipio que residió y ejerció la docencia, recibió homenajes y una calle fue rotulada con su nombre. Igualmente, según nos relató Baldomera como funcionaria más joven fue automáticamente concejal del ayuntamiento, elegidos los concejales se procedió a la elección de alcalde y recayó sobre ella3 Cuando la nombraron alcaldesa tenía 23 años.

Mi primera tarea fue hacer una carretera, en un principio fue una pista de tierra hasta Ravelo y actualizar el cobro de la contribución. Tuve problemas con las contribuciones, pues muchos vecinos se molestaron por la recaudación de tributos y hasta fui represaliada por ello. Pasé al cobro unos recibos de unas fincas rústicas que eran propiedad de la Inspectora de Educación de la zona y ésta mandó a cerrar la escuela que regentaba. Entonces acudí al Gobernador Civil, y solventó el problema, mandó una orden para que la escuela fuera abierta inmediatamente (entrevista, junio 2005).

La prensa corrobora del siguiente modo ese episodio:

No podía faltar. Hay muchos envidiosos por ahí. El Gobernador recibió una denuncia. Se le decía en ella que la maestra no podía ostentar el cargo porque carecía de vecindad. Todo porque la muchacha vive con sus familiares, que están en el término de Tacoronte. Pura envidia. El Gobernador falló: "Un funcionario del Estado tiene la vecindad del lugar donde ejerce su función". Y la maniobra quedó en un mal deseo nada más (Centeno, 1933).

Baldomera recuerda que ser alcaldesa tuvo sus inconvenientes, porque entonces no era como ahora que tienen asignado un sueldo, a ella le costaba, pues tenía que estar pagando taxis para ir al ayuntamiento después de que acababa la jornada escolar. En la actualidad la familia ha querido mantenerla al margen de homenajes y reconocimientos, tampoco ha facilitado que desde la historia de la educación y desde la vertiente de la participación de las mujeres en la política pudiera expresar su opinión, preservándola en todo momento de la di-

3 Ayuntamiento del Sauzal (Tenerife). Libro de Actas n ${ }^{\circ}$ 1(10-V-1933 al 1-IV-1934). Acta inaugural. 
fusión de sus vivencias y publicidad por ostentar el cargo de alcaldesa. No fue fácil que la familia nos permitiera entrevistarla, fue una ardua labor llena de dificultades y en todo momento estuvo acompañada y muchas veces interrumpían su relato. No obstante, ella fue muy receptiva y comunicativa durante las distintas sesiones de la entrevista. Además percibíamos como nos transmitía su alegría al sentirse protagonista de una historia no contada y que ahora traspasaba el umbral del ámbito familiar y doméstico.

\subsubsection{Toda una vida de maestra rural}

La maestra Concepción García Suárez nació el 27 de junio de 1903 en La Laguna (Tenerife). Cursó estudios de magisterio entre 1919 y 1923. Tuvo varios destinos como maestra en diferentes núcleos rurales de Tenerife; vivió las carencias económicas de la época y las limitaciones propias de las mujeres. La primera escuela para la que fue nombrada fue la escuela de Tijoco el 8 de mayo de 1927, un caserío adscrito al municipio sureño de Adeje. Desde Santa Cruz se trasladó por barco (en una pequeña embarcación denominada "falúa" que se utilizaba para desplazamientos costeros o de cabotaje) hasta la Caleta de Adeje y luego en un burro hasta llegar a Adeje, el núcleo principal de población donde tomó posesión. Para llegar al pequeño núcleo de población donde se encontraba la escuela tenía que caminar por senderos porque no había carretera ni calles. La carretera general se construyó años más tarde y tampoco pasaba cerca de allí. Estuvo solo dos meses porque se presentó a las oposiciones, suspendió los exámenes y entonces enviaron a otra maestra como titular a la escuela de Tijoco.

Regresó a La Laguna para seguir estudiando y conseguir una plaza fija de maestra. Mientras preparaba las oposiciones se dedicó a impartir clases particulares en Santa Cruz. Logró aprobar en 1928 siendo destinada como Maestra en Prácticas a la escuela mixta de Arguayo, otro caserío rural del sur de Tenerife adscrito al municipio de Santiago del Teide muy mal comunicado (no hubo carretera asfaltada hasta finales de los sesenta) para realizar tres meses de prácticas. Durante varias horas viajó en coche por todo el norte de la isla hasta llegar a la cumbre de Erjos, donde estaba en obras el trazado de la carretera. Al casco de Santiago del Teide llegó la carretera de circunvalación de Tenerife en torno a 1930. Cuando llegó a Santiago del Teide se compró unos zapatos y fue caminando a Arguayo donde fue recibida con voladores por la gente del pueblo. Pero las prácticas se prolongaron, permaneció allí veinte meses porque la inspectora tardó en ir por la incomodad del transporte, de hecho llegó indispuesta.

La vida en Arguayo era muy dura, no había luz ni agua corriente. El agua se vendía en las ventas a un real la "cacharra" (recipiente reutilizable de latón). Tenía que trasladarme caminando a Chio, otro pueblo, para poder comprar lo que necesitaba. Acostumbrada a mi vida en la ciudad de La Laguna y, ante aquella realidad adversa, solicité traslado pero mi petición fue desestimada. Ante el disgusto por esa negativa me enfermé y tuve que ser atendida por el médico, que en aquel entonces se encontraba en el pueblo de Icod de los Vinos, que estaba muy lejos a unos 30 Km. Y era el más próximo El médico tuvo que subir y bajar la cumbre hasta llegar al pueblo. Tomé posesión oficialmente el 29 de octubre de 1931 (Concepción García Suárez)

En aquella época las maestras vivían acompañadas por un familiar o alguien de la vecindad. No estaba admitido socialmente que una mujer pernoctara sola.

En la casa donde vivía me acompañaba mi hermana, ella permaneció conmigo durante unos meses, luego se quedaba una niña del pueblo. Me acompañaba por las noches porque tenía miedo porque había sucedido un crimen por cuestiones familiares. Los domingos me trasladaba a Tamaimo y me reunía con la maestra para almorzar; todo el trayecto lo hacía andando por los caminos y laderas acompañada de la chica, no había ninguna actividad cultural. Cuando abrieron una pista de tierra que comunicaba Arguayo con Santiago del Teide (que distaba $5 \mathrm{Km}$.) y a la vez con la carretera que iba a Icod hacía el largo trayecto (4-5 horas) hasta La Laguna para reunirme con mi familia.

Arguayo era un caserío sureño con pocos recursos económicos donde sus habitantes vivían con muchas estrecheces y carencias. Algunas personas emigraban a Cuba a buscar mejor vida. Cuidaban 
cabras y atendían algo de agricultura de secano, arando la tierra, sachando y recogiendo, porque estaba situado en una zona de malpaís y había poca tierra cultivable, fue la zona por donde fluyó lava del volcán, Chinyero. El volcán después de 111 años de "tranquilidad eruptiva" entró en erupción el 18 de noviembre de 1909, fecha que coincide con la última erupción en la isla de Tenerife (BRITO, 2003; BARRERA, 2009), y arrasó con todo. Las cosechas mermaron de forma considerable: los higos pasados, las almendras, centeno, cebada, lentejas, alguna papa... no había mucho que recoger en aquella zona improductiva. Había tradición artesana en el pueblo, aunque la economía era muy pobre.

Las mujeres tenían tradición con la alfarería y con artesanía de cestería de caña, mimbre y junco. La fabricación de tejas de barro ocupaba a los hombres. También las mujeres recogían cochinilla de las pencas que vendían y llevaban cestos de higos picos hasta la costa para venderlos y comprar pescado que traían al pueblo. Los hombres hacían carbón y luego lo vendían, igual que el estiércol. Había panadería donde hacían pan y rosquetes para las bodas. Los domingos la gente se reunía en las ventas a cantar y tocar formando una parranda, luego se ponían a bailar (Concepción García Suárez).

La escuela también era pobre y las niñas asistían de forma irregular porque ayudaban en el hogar familiar. También acudían niños porque era una escuela mixta. Una casa vieja destartalada que no reunía condiciones higiénicas ni docentes albergaba a los setenta alumnos. De acuerdo con los criterios de la época separó a las niñas de los niños y les daba clase en turnos distintos. A las niñas les daba clase de 9 a 12 horas, les enseñaba labores. Por la tarde de 14 a 16 horas iban los niños y a ellos les enseñaba a leer, escribir y las cuatro reglas. Por la noche también daba clases a los chicos mayorcitos que tenían que trabajar y no podían ir en el horario. Los juegos de las niñas eran los propios de la época: el escondite, la gallina ciega, al pañuelito, al corro... los niños eran más acciones más fuertes, les gustaba correr, jugar a la guerra, luchadas (Concepción García Suárez).

La actividad profesional de la maestra Baldomera $\mathrm{M}^{\mathrm{a}}$ García Fuentes, nacida en Tacoronte (Tenerife) el 4 de marzo de 1908, fue breve porque acabó cuando se casó. Curso magisterio entre 1923-1927.
Ejerció dos años de maestra rural en el pueblo de Ravelo, barrio del municipio del Sauzal.

Fui la primera maestra de Ravelo (El Sauzal), pero no había edificio escolar, habían habilitado una casa vieja que tenía una pizarra, una mesa y la silla para la maestra, y unos bancos para las niñas. No disponía de nada más, carecía de libros y material didáctico, pero las niñas aprendían rápido con los pocos recursos que tenían. Tampoco había carretera, por lo que tenía que ir andando por los caminos, que en época de lluvias se hacían intransitables y tenía que sortear charcos. Me trasladaba desde Tacoronte, pueblo cercano donde residía con su familia, y después tenía que atravesar por unas "huertas" (campos de cultivo) para llegar a la escuela, se limpiaba los pies y cambiaba de zapatos cuando llegaba, pues se había llenado de barro. Tardaba más de una hora andando, la acompañaba una chica que trabajaba como empleada doméstica en su casa, la cual regresaba y volvía al mediodía a llevarle el almuerzo (Baldomera $\mathrm{M}^{\mathrm{a}}$ García Fuentes).

Al año siguiente (curso 1934-1935) el destino fue en la isla de La Palma, pero su familia no le permitió que se trasladara, y no ejerció más. Después se casó y tampoco su marido le permitió ejercer la profesión. Según manifestó "eran otros tiempos y no se veía bien que las mujeres dejaran su casa para trabajar", aunque le gustaba la enseñanza, pero no renunció a las lecturas. Su marido era abogado y fue el Secretario de la Audiencia Provincial de Santa Cruz de Tenerife. Permaneció alejada de toda actividad pública y profesional.

\subsection{Maestras formadas en el plan de estudios de 1950}

La ruptura política que representó el franquismo en España con la etapa anterior se proyecto a todos los niveles de la vida del país. La guerra civil había dejado un país desolado, castigado y empobrecido. No solo la pérdida de vidas humanas sino la persecución a la democracia y a sus seguidores, a todas aquellas ideas que consideraban peligrosas para el orden autoritario que instauraron. El exilio y el empobrecimiento educativo y cultural constituyen un elemento clave en la dictadura. El magisterio se depuró y se redujo la formación; se elaboraron planes de estudios cargados de los valores ideológicos 
del nacional catolicismo. Los planes de estudio de la posguerra sólo requerían tener conocimientos de enseñanza primaria para acceder a las escuelas de magisterio y tenían preferencia los adeptos al régimen. A los familiares de "rojos" (=republicanos) o simpatizantes de ideas progresistas les estaban vetados los estudios. La precaria preparación de los maestros y maestras se constata también en el plan de estudios de 1942 .

Por decreto de 7 de julio de 1950 se estableció el plan de estudios de 1950, uno de los planes más longevos en la historia curricular de la formación del profesorado, y que responde a lo preceptuado en la Ley de Educación Primaria de 1945. Con el Plan 1950 se intenta mejorar el nivel formativo de los aspirantes a maestros exigiéndose haber cursado el bachillerato elemental para poder acceder a estos estudios. Después del Plan Profesional promulgado en la II República, fue el primer plan de estudios que incorpora el requisito de acceso de estar en posesión del título de bachiller elemental para ingresar en las Escuelas de Magisterio. Como innovación introduce la obligatoriedad de la asistencia del alumnado de Magisterio al campamento (curso de verano) que organizan el Frente de Juventudes y la Sección Femenina, los cuales emitirán el correspondiente documento acreditativo imprescindible para la tramitación del título de Maestra o Maestro.

Recogimos la memoria de tres maestras que cursaron el plan de estudios de 1950 en la Escuela de Magisterio Femenino "Nuestra Señora de Candelaria" en La Laguna (Tenerife), y ejercieron en zonas rurales:

1) María Darias Abreu (El Hierro, el 17 de octubre de 1925). Hija de un maestro recibió una formación tardía, pues su padre ejercía en El Hierro y la carencia de un centro de Bachillerato en aquella isla y las dificultades económicas para trasladarse a Tenerife le impidió titularse antes. Cuando a su padre se le concede traslado a Tenerife inicia los estudios de bachillerato. Ingresó en la Escuela de Magisterio "Nuestra Señora de Candelaria" de La Laguna en 1954, siguiendo el Plan de Estudios de 1950, concluyó en 1957. Como profesional ejerció la docencia en municipios del norte de Tenerife.

2) Gloria García Martín (Tacoronte, 6 de julio de 1933). Cursó el bachillerato superior $\left(6^{\circ} \mathrm{y}\right.$ Reválida) en el Instituto de La Laguna (Tenerife), aunque para estudiar magisterio sólo se requería el bachillerato elemental ( $4^{\circ}$ y reválida). Estudió magisterio entre 1957-1960. Fue maestra rural en los pueblos de las islas de La Palma y La Gomera.

3) Luisa Pérez Guerra (Santa Cruz de Tenerife, 4 de marzo de 1943). Procedía de una familia de comerciantes de Santa Cruz de Tenerife. Estudió en la Escuela de Magisterio Femenino de La Laguna, cursó el Plan de 1950, comenzó en 1961 y terminó en 1964. En 1965 aprobó las oposiciones y fue nombrada como maestra alfabetizadora en las cátedras ambulantes de la Sección Femenina, puesto que desempeñó hasta 1970. Estuvo trabajando como maestra en diferentes pueblos del norte de la isla de Tenerife.

En 1964 fui desplazada a la escuela unitaria de niñas en un pueblo del norte de la isla de Tenerife, de hábitat disperso, pobre y atrasado, con pocos recursos, eminentemente agrario y bastante población emigrada a Venezuela y Europa (Alemania, Holanda, Inglaterra). No disponía de servicios, no había farmacia ni tiendas y las "ventas" apenas suministraban algunos artículos de primera necesidad.

La gente era pobre y supersticiosa, tenían pocos hábitos de higiene, muchas niñas iban sucias y la cabeza llena de piojos. La mayoría de las casas no tenía agua corriente. Para mantener un poco la apariencia igualitaria y la limpieza les puse un uniforme, como un baby de tela rayitas azules, con manga larga, abotonadura trasera y un lazo amplio en el cuello, parecía un vestidito y así iban todas iguales. Al principio hizo una reunión con las madres, no asistieron muchas y le explicó que quería ponerles uniforme, porque era más cómodo y tampoco era caro (María Darias, junio 2005).

Las maestras eran conocedoras de las rutinas cotidianas de los pueblos donde transitaron. El comportamiento era propio de la época. Las actividades y la vida estaba sexuada, había espacios, conductas y valores diferenciados entre hombres y mujeres, una doble moral en orden al sexo. La distinta óptica de las obligaciones dependiendo del sexo.

Los hombres después del trabajo se reunían en las ventas a jugar a la baraja o al dominó, y a beber unas "perras" de vino. Las mujeres quedaban en casa haciendo la cena, cuidando los niños o haciendo las labores domésticas. A veces un grupo de mujeres 
jóvenes iban por la tarde/ noche a bordar a la casa donde vivía, hablaban y se distraían un rato, mientras los maridos estaban en las ventas y luego pasaban a recogerlas (Gloria García, junio 2007).

La mayoría de los pueblos eran de mujeres, los hombres estaban emigrados en el extranjero, o se quedaban toda la semana fuera porque trabajaban en galerías en el sur y otros regresaban de noche a casa después de un intenso día. Las mujeres de ocupaban de los niños, el cuidado de la casa, a veces del trabajo agrícola, y de las personas mayores. Muchos niñas tenían que hacerse la comida y encargarse de la casa para después ir a la escuela (Luisa Pérez, mayo 2007).

En las épocas de recogidas y siembra de cosechas, la asistencia era irregular porque ayudaban a sus madres en el cuidado de la casa y sus hermanos pequeños. En cuanto tenían 12 ó 13 años dejaban de ir a la escuela, pero seguían manteniendo el contacto, iban por las tardes a bordar, llevaban su labor y se reunían en la escuela, utilizaban la terraza y en ocasiones también permitía que las alumnas mayorcitas las acompañaran trabajando su labor (María Darias, junio 2005).

Las niñas mayores no se interesaban por la lectura, leían revistas y novelas de amor, propias de su edad y de aquellos años. Ayudaban a preparar las exposiciones de trabajos a final de curso, presentaban los cuadernos y las labores que hacían las niñas. Luego invitaban a las familias a visitarlas, generalmente iban las madres y hermanas, casi nunca iban los padres (Luisa Pérez, mayo 2007).

Colaborabamos en las actividades extraescolares, íbamos de excursión en caminatas con la escuela de niños a zonas recreativas cercanas. También hicimos encuentros con escuelas de pueblos vecinos, eran jornadas de convivencia para niños, niñas y los maestros y maestras. En aquella época existía un rígido control social sobre las maestras, se vigilaba su conducta. Los fines de semana nos reuníamos los maestros y maestras de la zona, había un compañerismo exquisito, incluso salíamos de noche (Gloria García, junio 2007).

Las maestras anteriormente citadas impartieron enseñanza primaria de acuerdo con la normativa que fijaba la ley de enseñanza primaria. Aprovecharon los escasos recursos que tenían a su alcance, innovan y se adaptan a las transformaciones curriculares. Las maestras tuvieron que adaptarse a los programas educativos, actualizarse y prepararse como sucedió cuando se impuso la Ley General de Educación en 1970, reforma educativa realizada por los tecnócratas aún bajo la dictadura de Franco y que estableció la enseñanza mixta. Todas se habían formado en un currículum sexista y con materias diferenciadas por sexos, con asignaturas específicas como la economía doméstica y las labores para las niñas y los trabajos manuales para los niños.

\section{Conclusiones}

Los relatos que acabamos de presentar demuestran que estas mujeres dejaron su impronta en los pueblos rurales de las Islas Canarias (España) donde les tocó ejercer la profesión de maestras. Constituyen una muestra representativa del ayer, de la autoconciencia educativa que no tenía implicaciones políticas ni ansiaban cambios de gobierno porque se hallaban ajenas a la gestión pública. Cuando se reunían lo hacían para solventar los problemas propios de la escolaridad pero escapaban a los intereses feministas, porque ellas mantenían el orden y contribuyeron a reproducir el discurso dominante. Es cierto que desarrollaron lazos afectivos entre ellas, desplegaron una cohesión y un sentimiento de pertenencia, una complicidad profesional y humana, un vínculo que en cierta medida las fortalecía como personas en ese proceso vital que las había alejado de su entorno familiar. Evidentemente no estaban autorizadas para transgredir las reglas de una sociedad masculina que les había reservado un espacio en la enseñanza, que no era otra cosa que una prolongación de su rol doméstico. No podían invalidar el orden vigente, con su tarea lo perpetuaron y se acomodaron a las exigencias sociales, porque en un contexto hermético y conservador debían mantener sus funciones para no "desclasarse". Incluso en el lustro republicano las transformaciones de género fueron comedidas y se apreciaron pocos cambios.

Todas las maestras entrevistadas desempeñaron un papel crucial en la enseñanza pero también en la vida cotidiana de los pueblos. Entregadas a la profesión, siempre pendientes de la escuela. En ocasiones las dificultades a las que las enfrentaba la vida cotidiana las fortalecieron y las 
convirtieron en indestructibles. El recuerdo de su trayectoria profesional no pasó inadvertida para cuantos las conocieron, tanto para sus alumnos y alumnas como para la vecindad. Estuvieron en activo durante épocas cruciales de la historia de España. En la etapa final de la monarquía del rey Alfonso XIII, la Segunda República y la dictadura franquista. Las maestras que ejercieron de Alcaldesas en la etapa republicana demostraron, en el breve tiempo que ostentaron el cargo, su capacidad gestora en beneficio de los pueblos y su gente. Su acercamiento a la política municipal y a las autoridades insulares y provinciales que apoyaron sus acciones no ha pasado desapercibida, incluso para las siguientes generaciones. Aún se las recuerda, incluso distinguiéndolas con el nombre de "la alcaldesa" a ellas y sus familiares. Pero la mayoría de las maestras entrevistadas ejercieron en el tramo final del franquismo, vivieron "vigiladas" por las autoridades y la propia vecindad, cuando aún la dictadura amordazaba a la enseñanza y la acción educativa del magiste- rio. Luego llegaron tiempos mejores y los aires renovadores traspasaron los muros de las escuelas. Después de la muerte del dictador, la transición y la instauración democrática renovaron la acción educativa y también mejoraron la vida de las maestras. Sin embargo, quedan muchas historias por contar y muchas vivencias por rememorar.

A través de la historia han sido las maestras en las zonas rurales, las primeras en sustraer de los brazos de la ignorancia a los niños y niñas. Pocas veces se escucha las voces de las protagonistas, las historias de su vida que transmiten sus vivencias, que muestran algunos hitos formativos. Relatos subjetivos de experiencias también subjetivas, que nos transmiten, desde su mirada al pasado, vivencias cargadas de emociones. Porque la historia oral, fuente viva de información, aunque limitada por la vida de la informante, pero de no valorar la aportación del recurso de la palabra nos impediría conocer esa rica experiencia femenina ilustrada de un protagonismo que dejó huella en las generaciones de alumnas que formaron.

\section{REFERENCIAS}

ALDECOA, J. Historia de una Maestra. Barcelona: Anagrama, 1991.

BARRERA, J. L. El centenario de la erupción del volcán Chinyero en Tenerife. Revista Tierra y Tecnología, Madrid, n. 35, p. 3-23, 2009.

BRITO, M. Erupción del Chinyero a través de la prensa. Tenerife: Llanoazur, 2003.

CENTENO, F. ¡Sí las mujeres mandasen! La Prensa, Santa Cruz de Tenerife, 9 feb. 1933.

CUESTA BUSTILLO, J. Las capas de la memoria.Contemporaneidad, sucesión y transmisión generacionales en España (1931-2006). Hispania Nova - Revista de Historia Contemporánea, Madrid, n. 7, 2007.

ESCOLANO, A. Las culturas escolares del siglo XX. Encuentros y desencuentros. Revista de Educación, Madrid, p. 201-218, 2000. Número extraordinario.

FLECHA, C. (Org.). Treinta Retratos de Maestras. Cuadernos de Pedagogía. Madrid: Cisspraxis, 2005.

FRASER, R. La Historia Oral como historia desde abajo. Revista Ayer, Madrid, n. 12, p.79-92, 1993.

GONZÁLEZ PÉREZ, T. Las Escuelas de Magisterio en La Laguna. La Laguna de Tenerife: Excmo. Ayuntamiento, 1997.

. Trazos históricos en la formación de maestros. Revista Interuniversitaria de Formación del Profesorado, Zaragoza, n. 21, p. 175-198, 1994.

; ENEBRAL CASARES, A. M.; PIKAZA, X. Mujer y Educación en Canarias. Notas históricas. Santa Cruz de Tenerife: Benchomo, 1998.

Las Escuelas Normales en La Laguna: 1936-1946. Una década en la formación del magisterio. Anuario de Estudios Atlánticos, Madrid, n. 46, p. 167-234, 2000.

La formación de las mujeres en la posguerra española. Canarias como ejemplo. Bordón - Revista de pedagogía, Madrid, v. 53, n. 3, p. 369-386, 2001. 
La voz del olvido. Maestras de ayer. Las Palmas de Gran Canaria: Anroart, 2008.

; LÓPEZ PÉREZ, O. (Coords.). Educación rural en Iberoamérica. Experiencia histórica y construcción de sentido. Las Palmas de Gran Canaria: Ediciones Anroart, 2009.

GOODSON, I. (Editor). Historias de vida del profesorado. Barcelona: Octaedro, 2004.

GUZMÁN, M. Cómo se han formado los maestros. Cien años de disposiciones oficiales. Barcelona: Prima Luce, 1973.

Vida y muerte de las Escuelas Normales. Barcelona: PPU, 1986.

IMBERNÓN, F. Vidas de maestros y maestras. Barcelona: Grao, 2005.

MELCÓN, J. La formación del profesorado en España (1837-1914). Madrid: M.E.C, 1992.

MOLERO PINTADO, A. Las Escuelas Normales de Magisterio: un debate histórico en la formación del maestro español (1839-1989). Madrid: Secretariado Publicaciones de Alcalá de Henares, 1989.

ORAMAS, J. A. La Escuela Normal de La Laguna en el siglo XIX. Santa Cruz de Tenerife: Aula de Cultura, 1992.

VATTIMO, G. La sociedad transparente. Barcelona: Paidós, 1991.

Recebido: 10.06 .2011

Aprovado: 30.08.2011 